\title{
Produção do espaço e os fundamentos da dinâmica territorial contemporânea: reestruturação, concentração, centralização e fragmentação
}

Production de l'espace et les fondamentaux de la dynamique territoriale contemporaine: restructuration, concentration, centralisation et fragmentation Producción del espacio y los fundamientos de la dinámica territorial contemporánea: reestructuración, concentración, centralización y fragmentación Space production and the foundations of contemporary territorial dynamics: restructuring, concentration, centralization and fragmentation

\section{Juliana Luquez}

\section{(2) OpenEdition}

\section{Journals}

\section{Edição electrónica}

URL: http://journals.openedition.org/espacoeconomia/5980

DOI: 10.4000/espacoeconomia.5980

ISSN: 2317-7837

\section{Editora}

Núcleo de Pesquisa Espaço \& Economia

\section{Refêrencia eletrónica}

Juliana Luquez, «Produção do espaço e os fundamentos da dinâmica territorial contemporânea: reestruturação, concentração, centralização e fragmentação », Espaço e Economia [Online], 14 | 2019, posto online no dia 12 agosto 2019, consultado o 06 setembro 2019. URL : http://

journals.openedition.org/espacoeconomia/5980 ; DOI : 10.4000/espacoeconomia.5980

Este documento foi criado de forma automática no dia 6 Setembro 2019.

(c) NUPEE 


\section{Produção do espaço e os fundamentos da dinâmica territorial contemporânea: reestruturação, concentração, centralização e fragmentação}

Production de l'espace et les fondamentaux de la dynamique territoriale contemporaine: restructuration, concentration, centralisation et fragmentation Producción del espacio y los fundamientos de la dinámica territorial contemporánea: reestructuración, concentración, centralización y fragmentación

Space production and the foundations of contemporary territorial dynamics: restructuring, concentration, centralization and fragmentation

Juliana Luquez

\section{Introdução}

1 A última década do século XX e a primeira do século XXI compreendem o intervalo de tempo no qual é possível perceber intensas transformações espaciais pelas quais os espaços metropolitanos vêm passando dada a intensificação das dinâmicas dos processos em curso. A relação dos vários processos espaciais com o da produção do espaço merece novo destaque nas pesquisas sobre a metrópole e sua região, pois é na análise das implicações desses processos que alcançamos possíveis compreensões sobre as complexidades da nova configuração metropolitana. Elegemos para a análise desta problemática os processos de concentração e centralização da dinâmica territorial das atividades urbanas na área metropolitana fluminense - sob o pressuposto da dispersão e fragmentação de sua conformação espacial. 
2 As novas dimensões da lógica de produção do espaço metropolitano inserem-se na relação entre a dinâmica territorial das atividades urbanas e a centralização de comando, gestão e fluxos (materiais e imateriais) e as implicações dessa relação na reestruturação do espaço. A partir dessa relação poderemos colaborar para a compreensão do processo de reestruturação do espaço manifesto pela reprodução do fato urbano de caráter metropolitano. Para tanto, examinaremos algumas hipóteses e considerações apresentadas por autores que vêm debruçando-se sobre a problemática desses processos em áreas metropolitanas a fim de contribuir para o entendimento das complexidades da Metrópole Rio ${ }^{1}$ e sua região.

\section{Aglomeração metropolitana do Rio de Janeiro}

Inspirados, especialmente, nas análises, hipóteses e contribuições interpretativas de Lencioni, ao analisar a dinâmica metropolitana de São Paulo, e Davidovich, a do Rio de Janeiro, vimos que as transformações que configuram atualmente as novas diretrizes do urbano e das grandes aglomerações metropolitanas precisam ser analisadas com vista à uma compreensão da complexidade relacional dos processos espaciais em curso. Segundo essas autoras trata-se do debate a respeito da produção contemporânea do espaço (DAVIDOVICH, 2001a) e que converge para destacar algumas das características da metrópole que se metamorfoseia nesse contexto trazendo à tona a importância da apreensão de processos espaciais tais como o de concentração e de centralização (LENCIONI, 2008) sob a égide do fortalecimento da territorialidade do capitalismo financeiro nos espaços da metrópole contemporânea, inaugurando um novo ciclo de reestruturação e subordinando as continuidades do processo civilizatório na dimensão do fenômeno urbano. A relação estabelecida entre a dinâmica territorial de concentração das atividades urbanas e a centralização de comando, gestão e fluxos (materiais e imateriais) na Metrópole Rio permite-nos uma visão mais atenta para o processo de reestruturação do espaço fluminense.

Previamente destacamos a tendência e o fato novo na perspectiva da compreensão da produção do espaço metropolitano e sua conformação na urbanização contemporânea. Sendo a tendência a histórica concentração das atividades urbanas na cidade do Rio de Janeiro e com isso o fortalecimento de sua centralidade. 0 novo repousa no fato de que com a reprodução da metrópole em direção aos eixos principais de sua aglomeração metropolitana, novas centralidades se reforçam através de uma configuração espacial intensificada por integrações regionais cada vez mais determinantes para a reprodução do capital e da manutenção de sua lógica perversa flagrante no processo de produção do espaço e da vida.

5 A reafirmação da centralidade da Cidade do Rio de Janeiro na fase da urbanização contemporânea não aniquila as centralidades em sua área de influência e na periferia metropolitana, contudo, amplia as fossas da fragmentação entre os territórios urbanos da aglomeração, não os desintegrando, ao contrário, fortalecendo uma dinâmica de homogeneização periférica e de hierarquização dominante.

Uma breve introdução à geografia histórica do Rio de Janeiro nos possibilita fornecer um panorama à problemática atual. Para Freitag a cidade do Rio de Janeiro era uma "cidade de itinerâncias urbanas". Segundo a autora, tornou-se a primeira referência de metrópole, ainda no período colonial, passando a "sediar o imaginário da cultura 
europeia e portuguesa" (FREITAG, 2009, p. 30). Nessa época, do início até meados do século XIX, especialmente com a transferência da Família Real e a Corte Portuguesa para o Rio de Janeiro e todos os privilégios e impasses que essa transferência poderia trazer, a Cidade do Rio de Janeiro extravasa em suas funções política, cultural, portuária, comercial. O Rio de Janeiro foi sede de todas as formas de poder instituídas desde 1763, ainda no período Colonial, até a ascensão de Juscelino Kubitschek, governo no qual se deu a transferência da capital federal do Rio de Janeiro para Brasília, em 1960.

De Capital Federal (1763-1960) à Estado da Guanabara (1960-1974) à Capital do Estado do Rio de Janeiro (1975 até o presente). Todas as funções citadas acima contribuíram para a efervescência do urbano no Rio de Janeiro. 0 Rio de Janeiro teve sua evolução urbana alavancada por circunstâncias históricas e o desenvolvimento de suas funções proporcionado pela intensidade dos fenômenos políticos, econômicos e socioculturais responsáveis pela dinamização do seu território e pela autonomização da cidade - este último com reflexo negativo na integração territorial com o Estado do Rio de Janeiro após a transferência da capital para Brasília e a fusão entre os Estados da Guanabara e do Rio de Janeiro (DAVIDOVICH, 1999). A partir do final do século XIX e as primeiras décadas do $\mathrm{XX}$ que as transformações na Cidade do Rio de Janeiro e nas suas aglomerações imediatas e intermediárias ganham efeitos estruturantes para uma conformação espacial urbanoregional (ABREU, 2008; VIANA, 2013).

8 O Rio de Janeiro seguia como centro de poder e de riqueza, desenvolvendo para além de sua função político-administrativa, a centralização dos negócios e exportação do café, introduzidos em terras do Vale do Paraíba (leito do principal eixo rodoviário entre RioSão Paulo). A expansão da cafeicultura e o movimento comercial desenvolveram, a partir do principal elemento estruturante da urbanização paulista, a ferrovia, uma rede de cidades que impulsionou as mais profundas transformações no território de São Paulo. Esse conjunto de transformações proporcionou à economia urbana de São Paulo um fortalecimento que não ocorreu no Rio de Janeiro, onde a manutenção do trabalho escravo nas lavouras não oportunizou o mesmo efeito que em São Paulo com a mão de obra do imigrante (MONBEIG, 2004; MARTINS, 2010). Já na década de 1920, o Rio de Janeiro começa a perder importância em relação a São Paulo que, com o status de "locomotiva do Brasil", torna-se o centro dos negócios do café, da indústria e dos serviços financeiros, respectivamente. Apesar da perda de importância no cenário nacional já a partir dos anos 1920 (NATAL, 2003) o Rio de Janeiro estabelece com São Paulo um eixo dinamizador a partir do qual o processo de urbanização passa a agregar uma série de novas funções urbanas, novas formas e uma estrutura regional complexa, provenientes da contínua herança histórica de concentração das atividades urbanas por aquela cidade e do sucesso da cafeicultura por essa² ${ }^{2}$.

9 Nesse sentido apresenta-se a tendência a qual nos referíamos anteriormente: a cidade do Rio de Janeiro possui aspectos históricos que a evidenciam em detrimento de outras cidades e metrópoles brasileiras e de sua própria aglomeração metropolitana, por nela gravitar a concentração e a centralização das atividades urbanas há mais de dois séculos. As funções que exerceu no passado a colocaram em conexão com o externo, devido as suas atividades político-administrativas e comerciais e nessa atual fase da urbanização metropolitana, continua a exercer conexão com o de fora, agora em uma perspectiva da globalização da economia e do capitalismo financeiro, pondo-se o desafio, também histórico, dos limites do crescimento econômico fluminense sustentado na sua metrópole e da pouca densidade produtiva de sua região (SOBRAL, 2015a; 2015b). 

(mas não exclusivamente) a Cidade do Rio de Janeiro e sua aglomeração metropolitana, refere-se a reestruturação da tradicional área metropolitana do Rio de Janeiro, que representa territorialmente a expressão da região urbana fundida na linearidade do eixo centro-periferia. Tanto a configuração territorial quanto a interação dos processos globais de reprodução do atual momento do capitalismo, refazem-se sob as heranças dos processos históricos de evolução urbana e desenvolvimento das atividades econômicas no contexto da urbanização e da industrialização ao longo do século $\mathrm{XX}$, subordinando formas e funções arcaicas. Diante de um mais alto patamar do processo de urbanização, a metrópole supera a cidade e supera a si mesma quando ao se manter centro permite a criação de novos centros, ou quando ao se tornar dispersa regula a produção e a valorização dos capitais envolvidos na produção, centralizando o comando e a gestão dos fluxos materiais e imateriais envolvidos nesta produção - incluindo a produção do próprio espaço.

11 Verdadeiramente assistimos à conformação de um fato novo, marcado pelo fortalecimento de tendências que intensificam os processos espaciais de concentração e centralização das atividades urbanas e do capital na Metrópole Rio em detrimento de sua aglomeração metropolitana. Isso porque, os processos de concentração e centralização renovaram a função de comando, gestão e controle da Metrópole Rio. Especialmente porque sob a função da metrópole contemporânea repousa a racionalidade da acumulação capitalista, diante da qual o caráter social dos produtos só se manifesta a posteriori, nas trocas comerciais, pois as forças produtivas estão dispersas e os processos de produção não estão coordenados (AGLIETTA, 1986). Entretanto, essa integração se dá na concentração e na centralização do capital e do trabalho.

12 A concentração permite a ampliação da acumulação e a centralização garante uma alternativa a concorrência, mantendo, por vezes, o produto, mas associando diferentes capitais, ampliando o poder de decisão, gestão e comando. A desconcentração territorial das indústrias fluminenses (ou mesmo o movimento de desindustrializaçãoreindustrialização) da área metropolitana em direção as áreas de dispersão da atividade produtiva não contradizem o circuito de concentração e centralização do capital na Metrópole Rio. Isso por dois motivos específicos. Primeiramente, no que se refere ao movimento de acumulação global, que flexibiliza a produção e o trabalho, mas regula a concorrência e garante a centralização do capital. Em segundo, porque permite que, com a dinamização da economia global através dos serviços de inteligência computacional e a ampliação do aporte tecnológico de distribuição de informação e comando, a direção das forças produtivas possam se alargar para além do seu centro gestor sem qualquer prejuízo a produtividade.

13 É importante considerar a observação feita por Davidovich em relação ao estado do Rio de Janeiro, afirmando que "as indústrias (...) e outras atividades, que compõem a configuração espacial daquele território, tem sede ou representação principal na cidade do Rio de Janeiro" (DAVIDOVICH, 2001a; p. 328). Isso reforça o que vimos apresentando até aqui. $\mathrm{O}$ desenvolvimento das economias de aglomeração e a dispersão das atividades produtivas ao longo dos eixos de circulação do território fluminense tenderam a estreitar a dependência dessas economias em relação à Metrópole Rio em um processo de concentração e centralização do capital. A dispersão de unidades produtivas pelo território não comprometeu a centralidade da metrópole fluminense. Como aponta Lencioni "este espraiamento das atividades foi historicamente proporcionado pela 
tecnologia, principalmente por aquelas capazes de processar e explorar informações, permitindo unir a descontinuidade espacial do processo de produção" (LENCIONI, 1994, p. 59).

14 No caso específico da Metrópole Rio, o setor de serviços tem uma particular importância pois uma das maiores demandas do mercado e da economia global no que diz respeito ao aparelhamento e suporte à produção se revela pelo setor de serviços, especialmente o de transporte e de telecomunicação. A cidade do Rio de Janeiro tem nesse índice um dos elementos de fortalecimento de sua centralidade e de sua função como centro de comando e gestão, especialmente a partir dos serviços modernos de logística e informação. Como destaca Davidovich

Rio de Janeiro e São Paulo [...] estariam deixando de ser a sede da produção propriamente dita, como sucedeu no auge do processo urbano-industrial, para se posicionarem como centros de controle e gestão e polos de serviços avançados, que atendem aos interesses da grande empresa" (DAVIDOVICH, 1999; p. 6).

15 Davidovich ressalta a singularidade histórica do processo de estruturação da Metrópole Rio, sua relação com a conformação de sua região metropolitana e o interior do estado fluminense. A concentração de atividades, pessoas, renda, trabalho e tecnologia na capital fluminense agravou a fragmentação territorial e "traduz a contradição entre a posição urbana sucessivamente acumulada pela cidade do Rio de Janeiro e o isolamento secular mantido em relação à sua interlândia imediata" (DAVIDOVICH, 2001b, p. 69).

16 Ainda sobre esse aspecto, o economista Sobral, acrescenta que 1) a fragilidade institucional do estado do Rio de Janeiro em planejar uma política metropolitana, 2) a fraca densidade produtiva da periferia metropolitana e 3) o dinamismo econômico apoiado, principalmente, nas atividades de serviços, que vêm se apresentando incapazes de incorporar mão de obra e gerar renda crescente, são os fatores que reforçam os impasses da dinâmica territorial fluminense e a centralização de comando, gestão e fluxos na Metrópole Rio (SOBRAL, 2015a). A "crise" se reforça mesmo diante do ciclo recente de grandes investimentos públicos e privados característicos da atual fase de reestruturação do espaço metropolitano do Rio de Janeiro ${ }^{3}$.

$17 \mathrm{Na}$ atual fase da urbanização, gerida pelas determinações contraditórias do capitalismo financeiro, o protagonismo da cidade do Rio mediante as demandas da economia global tem sido um dos desafios para o desenvolvimento das cidades metropolitanas e do entorno da região metropolitana do Rio. Neste sentido, Davidovich sinaliza alterações recentes na estruturação da Região Metropolitana do Rio de Janeiro (RMRJ). Sua tese aponta para uma reestruturação setorizada do espaço. A saber: 
Primeiro setor de reestruturação da RMRJ

-Refere-se à cidade do Rio de Janeiro e sua esmagadora concentração de empreendimentos e iniciativas de reestruturação socioespacial. Destacando-se, sem precedentes, a Zona Leste na Cidade, especialmente os bairros da Barra da Tijuca, Jacarepaguá e Campo Grande

Segundo setor de reestruturação da RMRJ

-Refere-se ao eixo comandado por Niterói, na porção oriental da Baía de Guanabara, destacando-se ainda os municípios metropolitanos de São Gonçalo, Itaboraí e Maricá

\section{Terceiro setor de reestruturação da RMRJ}

- Refere-se a Região da Baixada Fluminense, onde os eixos de comunicação viária tendem a reforçar as relações já estabelecidas desta porção do território metropolitano com a metrópole fluminense. Neste setor estão incluídos os municípios de Belford Roxo, Duque de Caxias, Guapimirim, Itaguaí, Japeri, Magé, Mesquita, Nilópolis, Nova Iguaçu, Paracambi, Queimados, São João de Meriti e Seropédica

Elaboração própria a partir de DAVIDOVICH, 1999.

EMBED Excel.Chart.8 \s É importante ressaltar que este contexto de reestruturação tem produzido novos nexos de integração no território fluminense. Essa é uma consideração importante, pois vai ao encontro das considerações que tecemos até aqui, especialmente no alinhamento da perspectiva interpretativa de compreensão da produção contemporânea do espaço a partir da dinâmica de reestruturação do espaço, pela qual o processo de metropolização inaugura os eixos de dispersão, ampliando as relações de reprodução do capital na realização da urbanização e fortalecendo os laços (real e virtual) com a globalização.

A aglomeração metropolitana do Rio de Janeiro considerando o território institucionalizado de sua Região Metropolitana, conforme atualização em 2013, é composta por 21 municípios, sendo eles: Rio de Janeiro, Belford Roxo, Cachoeiras de Macacu, Duque de Caxias, Guapimirim, Itaboraí, Itaguaí, Japeri, Magé, Maricá, Mesquita, Nilópolis, Niterói, Nova Iguaçu, Paracambi, Queimados, Rio Bonito, São Gonçalo, São João de Meriti, Seropédica e Tanguá. Sendo a população total do Estado do Rio 16.369.178, sua população metropolitana é de 12.064 .084 , o que equivale a $73,7 \%$ de sua população total. Além da Metrópole Rio, com 6.422.922 habitantes, o destaque está para os municípios de São Gonçalo (1.025.507 habitantes), Duque de Caxias (873.921 habitantes), Nova Iguaçu (804.815 habitantes) e Niterói (494.200 habitantes). ${ }^{4}$

A concentração populacional nesses municípios tem sua razão no processo de industrialização do território fluminense e na consequente transformação do espaço das cidades entre as décadas de 1930 a 1980 consolidando a urbanização no em torno da Baía de Guanabara e expandindo os eixos de dispersão metropolitana para os demais municípios resultando na conurbação das áreas ocupadas na orla ocidental e oriental da Baía de Guanabara (GEIGER, 1956).

Vemos na aglomeração metropolitana do Rio de Janeiro uma conformação a partir de eixos radiais, inicialmente consolidados na faixa litorânea da orla ocidental da Baía de Guanabara, expandindo a urbanização para os subúrbios contínuos e descontínuos da cidade do Rio de Janeiro, entre os maciços da Tijuca, da Pedra Branca e de Gericinó e a porção leste da Guanabara. A orla oriental da Baía de Guanabara, o maior eixo 
descontínuo da urbanização fluminense, teve sua consolidação urbana na forma de conurbação entre os territórios de Niterói e São Gonçalo. A industrialização nessa região construiu para si a urbanização que precisava, caracterizada pela instalação de uma forte infraestrutura portuária, ferroviária e bondes, vilas operárias, parques industriais, comércio, escolas operárias, cinemas, etc. Mendes destaca a estreita relação que se estabeleceu entre os municípios de São Gonçalo e Niterói. Devido à expansão urbana proporcionada pela conurbação de alguns bairros operários, especialmente, Neves (São Gonçalo) e Barreto (Niterói), o autor as descreve como "cidades gêmeas" e acrescenta que a vida urbana que se desenvolveu em Niterói também se desenvolveu em São Gonçalo mediada pelo processo de industrialização do território fluminense (MENDES, 1950).

A conurbação verificada na aglomeração metropolitana do Rio de Janeiro como forma espacial da reprodução da Metrópole Rio policêntrica, ressalta a dominação de "superposições e justaposições de espaços com tendências à conformação de territórios demarcados que resultam das inclusões produtivas no processo social" (SEABRA, 2003, p. 9). Ora, se considerarmos o urbano como o processo social em curso e em vias de realização, as inclusões produtivas referem-se as centralidades da totalidade da realidade urbana fluminense que passam a compor o espaço das contradições no movimento da reprodução da metrópole. Em outras palavras, vemos erigir na complexidade metropolitana a relação entre dispersão e fragmentação, reforçando a concentração e a centralização da Metrópole Rio; todos esses processos característicos da metropolização do espaço fluminense.

Para Lencioni

o processo de metropolização do espaço se expressa na intensificação e multiplicidade dos fluxos de pessoas, mercadorias e informações, bem como pelo crescimento do número de cidades conurbadas, onde não se distingue muito bem, na continuidade da área construída, o limite municipal de cada uma delas. E, também, pela expansão territorial do aglomerado metropolitano e pela extensão e densificação territorial da concentração das infraestruturas. (LENCIONI, 2011, p. 136).

24 A análise das dinâmicas territoriais contemporâneas, no contexto da metropolização fluminense, auxilia-nos na problematização da realização da sociedade urbana e do espaço como produto, meio e condição dessa realização (CARLOS, 2011). As características acima descritas pela autora conduzem-nos para a compreensão do caráter difuso e fragmentado da conformação metropolitana no Rio de Janeiro.

\section{O caráter difuso e fragmentado da conformação metropolitana do Rio de Janeiro}

25 O caráter difuso da aglomeração metropolitana do Rio de Janeiro verifica-se a partir da identificação dos eixos de conformação e expansão da urbanização no em torno da Baía de Guanabara (mapa 1). Identificamos 6 (seis) eixos de dispersão e espraiamento da urbanização. Os eixos $A_{1}, B_{1}, C$ e D constituem os territórios de inclusão produtiva do primeiro momento da urbanização fluminense, aqui chamado de urbano-industrial. Os eixos $\mathrm{A}_{2}, \mathrm{~B}_{2}$, E e F constituem os territórios de inclusão produtiva do segundo momento da urbanização fluminense, aqui denominado metropolitano-financeiro. 
Mapa 1 - Rio de Janeiro: conformação e expansão da urbanização no em torno da Baía de Guanabara

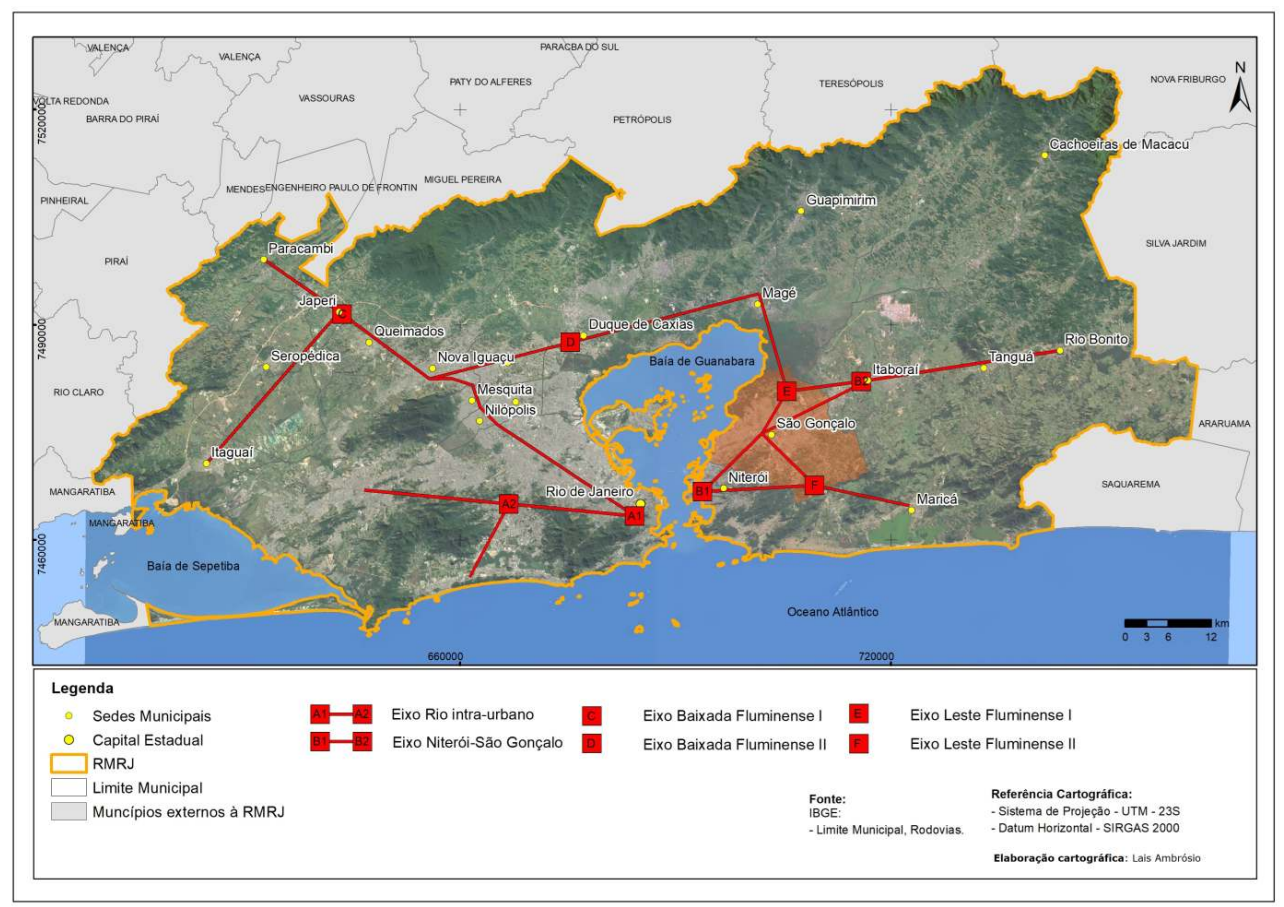

No que se refere ao momento urbano-industrial a urbanização apresenta-se como determinação histórica na constituição da sociedade moderna, este processo corresponde a consolidação do modelo de acumulação capitalista sob as condições gerais de produção da industrialização. A ruptura nas determinações históricas do movimento de urbanização, no qual irrompe o momento metropolitano-financeiro, inaugurando a sociedade pós-industrial ou sociedade urbana, no qual "a metrópole se coloca ao mesmo tempo como uma condição para a reprodução do capital, um meio utilizado para a sua reprodução e, ainda, um produto do próprio capital." (LENCIONI, 2011, p. 136).

O caminho da problematização da realidade urbana fluminense, proposto aqui pelas vias da compreensão do movimento de produção e reprodução da metrópole, encontra nas premissas acima o direcionamento para a identificação dos eixos de conformação e expansão da urbanização da Região Metropolitana do Rio de Janeiro bem como os nexos desses processos com o da reestruturação do espaço - este último, defendido aqui, como álibi da reprodução do capital no momento recente.

Os eixos $A_{1}, B_{1}, C$ e $D$, embora consolidados na inclusão produtiva do processo social de urbanização, ganham novas dinâmicas frente às estratégias de renovação da reprodução capitalista. Os eixos $\mathrm{A}_{2}, \mathrm{~B}_{2}$, E e F compõem as novas territorialidades do fato urbano, tendo o processo de metropolização sua maior síntese complexa. Os eixos $A_{1}, B_{1}$, C e D, consolidados sob a lógica de reprodução urbano-industrial, conferiram à Metrópole Rio alto grau de concentração e centralização considerando a articulação metrópoleaglomeração e as atividades urbanas. Ao mesmo tempo que as relações de produção reforçaram a concentração e centralização das atividades urbanas historicamente desenvolvidas na cidade do Rio de Janeiro manifestaram a policentralidade característica da metrópole capitalista na forma espacial da periferização, integrando estreitamente os territórios contíguos de Niterói e São Gonçalo, Nova Iguaçu e Duque de Caxias às lógicas e 
contradições da reprodução da metrópole, transformando tais municipalidades em complexidades urbanas do ponto de vista das relações de produção, propriedade e trabalho.

Aos eixos $\mathrm{A}_{2}, \mathrm{~B}_{2}$, E e F atribuímos uma dinâmica especulativa, característica do momento metropolitano-financeiro, fundado na negação da cidade e na valorização do urbano sob a forma espacial da segregação, insere à urbanização em sua fase mais complexa e ao mesmo tempo reforça suas continuidades históricas. Os refúgios tidos como seguros, sustentáveis e totalmente integrados à Metrópole Rio, distam algumas poucas dezenas de quilômetros do núcleo metropolitano, porém ligam-se apenas por caminhos rodoviários em sua maioria acessível somente por transporte próprio, o cotidiano passa a se reproduzir na imaterialidade dos fluxos (de dinheiro, de informação) e na materialidade da rede de cabos de fibra óptica que torna possível a penetração das atividades urbanas cada vez mais determinantes da vida cotidiana. As municipalidades de Magé, Guapimirim, Itaboraí, Tanguá, Rio Bonito e Maricá são exemplos dessa nova configuração da urbanização fluminense.

O espaço assume "uma espécie de realidade própria, da mesma maneira que a mercadoria, o dinheiro, o capital, mas de modo distinto" (LEFEBVRE, 2000, p. 35). Considerando a hipótese de Lefebvre sobre o espaço como produto social, vamos em busca do modo distinto como o espaço assume essa realidade autônoma no momento histórico de produção capitalista, e produz assim o espaço, o seu espaço de reprodução.

31 O espaço se torna, na fase atual da urbanização contemporânea - a metropolização - o produto com maior valor social agregado e as cidades tornam-se a possibilidade concreta de extração de mais valia e de transferência de valor. Se retornarmos ao mapa 1, veremos que os eixos de conformação e expansão da urbanização fluminense são, em verdade, os eixos de reestruturação do espaço, mas não de todo o espaço e sim de porções do espaço. Logo, destacamos a reestruturação do espaço como sendo a possibilidade interpretativa do "modo distinto", ao qual se refere Henri Lefebvre em relação a realidade própria do espaço, ou seja, o caráter reestruturante do valor no processo de produção do espaço.

Maricato nos fornece um exemplo da formulação teórica acima apresentada. Para a autora, a urbanização dos baixos salários, característica das cidades da periferia do capitalismo, é marcada pela construção da moradia como forma de produção doméstica e, na maioria das vezes, ilegal, paulatina e durante os horários de folga do trabalho remunerado. Os trabalhadores recebem pouco pela força de trabalho que vendem e nada pela construção de suas próprias moradias, ao contrário, todo o custo é retirado do seu salário. Essa situação, segundo a autora, é um exemplo não só de uma produção doméstica no contexto urbano, mas também de produção da cidade, de bairros, de cotidiano (MARICATO, 2015).

33 Mesmo os bairros operários, tradicionalmente populares, compostos por casas autoconstruídas não estão fora do processo de valorização, pois o trabalho requerido para a sua produção somado ao trabalho requerido na construção de infraestrutura urbana (vias de comunicação, equipamentos coletivos, comércio e serviços), ao longo do tempo incorporada, faz parte do processo de produção do espaço e da cidade e, portanto, de sua valorização. Se a classe trabalhadora, em um primeiro momento, produz a cidade como valor de uso, as relações sociais envolvidas no processo de produção - quer na fábrica ou na cidade - subordinam a então produção doméstica ao processo de revalorização, pois 

do seu valor de troca. Para eles, a cidade é mercadoria. É um produto resultante de determinadas relações de produção. Se lembrarmos que a terra urbana, ou um pedaço de cidade, constitui sempre uma condição de monopólio - ou seja, não há um trecho ou terreno igual a outro, e sua localização não é reproduzível - estamos diante de uma mercadoria especial que tem um atributo de captar ganhos sob a forma de renda. A cidade é um grande negócio e a renda imobiliária, seu motor central. (MARICATO, 2015, p. 23). Nova Iguaçu, Duque de Caxias e São Gonçalo, são exemplos da formulação teórica aqui apresentada. 0 espaço urbano construído nessas municipalidades teve como principal agente produtor, por um lado, a classe operária que se consolidou nos anos 1950, se diversificou pós-1960 e se transformou, nas últimas três décadas, em trabalhadores urbanos terciários, terceirizados e informalizados; por outro, os produtores imobiliários, os proprietários fundiários e dos meios de produção e o Estado, articulados, construíram cidades fragmentadas, homogeneizadas e hierarquizadas, cujo caminho da metropolização se faria possível com a concentração das atividades urbanas, a centralização de comando, gestão e fluxos no Metrópole Rio e com a dispersão territorial do fenômeno urbano nas áreas suburbanas e periféricas, para as quais a classe trabalhadora foi sendo assentada e, reproduzindo sua força de trabalho, produziu a regionalização da metrópole fluminense.

36 O processo de periferização da classe trabalhadora metropolitana fluminense inaugura eixos da Metrópole Rio em direção aos lotes de construções populares que uma vez consolidados agregam valor à terra urbana e dinamizaram o processo de valorização das áreas periféricas e suburbanas da metrópole enquanto realizava a dispersão e a fragmentação do território sob domínio da urbanização industrial. A função dormitório, como se convencionou chamar a dinâmica metropolitana de atração/influência entre um núcleo urbano principal e as cidades do seu em torno, é, em verdade, a consolidação do processo de estruturação urbano-industrial e berço da estruturação metropolitanofinanceira.

37 Nessas áreas destacam-se a dinâmica de revalorização do espaço na aglomeração fluminense, reforçando a fragmentação entre a Metrópole Rio e sua aglomeração metropolitana e realizando a dinâmica da produção do espaço em um movimento que se apreende pelos processos de periferização-espoliação-segregação. A periferização da classe trabalhadora, consolidando-se na expansão da industrial sob um modelo de acumulação contraditório entre o crescimento econômico e a pauperização absoluta ou relativa dos diversos segmentos da classe trabalhadora e aniquilando as formas históricas de apropriação social do espaço, incluindo a vida de bairro (SEABRA, 2003). A espoliação urbana, que vista pelas lentes do problema habitacional, constitui uma dimensão da exploração do trabalho e da exclusão cidadã. A segregação espacial, gestada nas relações sociais de produção e materializada como contradição urbana ${ }^{5}$ no processo de valorização diferencial da terra, que também caracteriza a especulação imobiliária na dinâmica de produção do espaço (KOWARICK, 2000).

38 É flagrante que a maior parte dos investimentos públicos é dirigida para as áreas onde vivem e trabalham as classes abastadas e que o processo de revalorização do espaço em áreas populares é uma via do movimento de reestruturação do espaço para maximizar a realização do capital e ampliar as condições gerais necessárias ao processo de acumulação. Por isso insistimos na formulação teórica que considera o processo de 
valorização como parte da exploração do trabalho e da exclusão cidadã da classe trabalhadora em relação à cidade que ela mesma produz. No caso das áreas urbanas em municipalidades periféricas essa produção da cidade é, por um lado, realizada pelas próprias mãos do trabalhador (residências autoconstruídas, bairros fundados por invasões e loteamentos clandestinos, ofertas populares ao acesso à terra) e, por outro lado, por sua capacidade de pressionar e obter do Estado, por meio de lutas sociais e reivindicações, os elementos indispensáveis à sobrevivência na cidade, estes também indispensáveis a reprodução da força de trabalho.

39 A engrenagem da reprodução do capital e de suas contradições não só expulsa a classe trabalhadora para longínquas áreas de possibilidades do modo de vida urbano (periferização) no momento da consolidação de uma estrutura de relações contidas na produção do espaço (espoliação), como também é capaz de reorientar o processo de valorização do espaço por meio da renovação das continuidades de seu movimento (segregação). Assim, estrutura-forma-função urbanas ganham um dinamismo no processo de produção do espaço que torna possível a afirmação de que as áreas periféricas ou os espaços populares, ontem produzidos pela classe trabalhadora, são, hoje, álibi de reestruturação do espaço para a sua revalorização, em um momento marcado pela iniciativa do Estado integralmente tomada pelos interesses privados (CHESNAIS, 1996). Outrora, "moradores espoliados e trabalhadores explorados" (KOWARICK, 2000, p. 35); ora, moradores segregados e trabalhadores precarizados, lançados à sorte da economia urbana terciária e sob o julgo da financeirização do capital. A metropolização fluminense consolidou um espaço fragmentado, homogêneo e hierarquizado. Se a centralização do comando, da gestão e dos fluxos reforçou a posição da Cidade do Rio de Janeiro em relação à sua aglomeração metropolitana pós-fusão, também subordinou aos interesses do capital a reprodução das contradições urbanas no eixo metropolitano sob a influência de Niterói. Nos territórios municipais do Rio de Janeiro e de Niterói encontram-se as áreas mais valorizadas da aglomeração metropolitana fluminense. Nas quais observa-se uma forte e intensa dinâmica especulativa com valores que chegam a ser de 5 (cinco) a 10 (dez) vezes maiores que em outras áreas da região metropolitana. Os empreendimentos imobiliários implantados nos bairros nobres das cidades do Rio de Janeiro e de Niterói, tanto residenciais quanto comerciais, respondem à demanda de mercado garantida por uma maior mobilidade social das classes mais abastadas e atendem à dinâmica de centralização e concentração das atividades urbanas nessas localidades, sobretudo na capital.

41 A atividade imobiliária mantém relação estreita com a dinâmica de produção do espaço na aglomeração metropolitana do Rio de Janeiro, especialmente, a partir dos anos 1930. Até essa época a produção de moradias era uma exclusividade da iniciativa privada. 0 provimento de habitação pelo poder público, dos anos $1930 \mathrm{em}$ diante, inaugura novos arranjos especulativos da atividade imobiliário. Por exemplo, em São Paulo, a cidade explode em periferias fundadas no trinômio loteamento-casa própria-autoconstrução (BONDUKI, 2013). No Rio de Janeiro, a explosão da cidade em direção aos subúrbios e freguesias rurais, deu-se pelo binômio trem-segregação proletária (FERNANDES, 2011). E, justamente, nesse movimento de expansão urbana, a atividade imobiliária encontrou seu limite e sua superação enquanto forma especulativa de produção do espaço.

Considerando a realidade urbana do Rio de Janeiro, se por um lado, produzia-se o espaço ao passo que produzia-se a habitação social, provida pela Estado e circunscrita na cidade do Rio de Janeiro, ao mesmo tempo e em contrapartida, outros espaços também eram 
produzidos fora da provisão do Estado - isso porque essa habitação social não se destinou, inicialmente, ao atendimento de classes populares e sim à camadas estabilizadas de funcionários dos governos, por exemplo. Na outra ponta da cidade e nos seus arredores se produzia uma periferia urbana, fragmentada, por isso excludente. Em São Gonçalo, na Baixada Fluminense e em algumas localidades de Niterói erguiam-se os bairros feitos pelas próprias mãos dos trabalhadores. São os bairros dos grandes loteamentos, da clandestinidade territorial, sem apoio técnico, a cidade ilegal (MARICATO, 2015).

\section{Considerações Finais}

Isto posto, acrescentamos que a periferização da classe trabalhadora se reforça com a difusão do modo de vida urbano na aglomeração fluminense onde poucos serviços coletivos estão à disposição de suas demandas, a espoliação urbana se amplia pelos raios dessa difusão e a segregação se manifesta via reestruturação do espaço no processo de valorização dos fragmentos da cidade. Os trabalhadores com renda mais baixa, com nenhuma ou pouca garantia de crédito para o financiamento de sua moradia, sem recursos à mobilidade urbana, são lançados cada vez mais para longe de áreas urbanas consolidadas e reinseridos na dinâmica de produção do espaço.

Ao mesmo tempo que a urbanização fluminense criou caminhos a partir de dois eixos de expansão das atividades urbanas, complexificou os nós das relações sociais contidas no espaço de consolidação da metropolização: entre os interesses das classes dominantes que detém os meios de produção e as políticas de influência de atração de investimentos públicos e privados e a produção de uma área metropolitana para assentar a classe trabalhadora necessária ao movimento de realização do capital - movimento este, combinando o caráter periférico, espoliador e segregador do atual modo de produção.

A reestruturação do espaço no período contemporâneo de sua produção, embora manifesta por uma ruptura da renovação da reprodução do capital, subordina elementos anteriores de valorização ao atual e reinicie o ciclo de valorização/revalorização perceptível pelo movimento de estruturação/reestruturação (VIANA, 2019). A transição da estruturação urbano-industrial para a metropolitano-financeira foi possível pela reestruturação do espaço, mas de porções do espaço. Reforçando a fragmentação sem superar as continuidades: periferização, espoliação e segregação a partir das quais a metrópole fluminense se reproduz. Dessa forma, aceleram-se os caminhos para a urbanização e descentraliza-se a aparência caótica e insuportável da metrópole, reproduzem-se as contradições e ampliam-se os territórios de seus domínios.

\section{BIBLIOGRAFIA}

ABREU, Maurício de Almeida. A evolução urbana do Rio de Janeiro. 4. ed. Rio de Janeiro: IP, 2008. 
AGLIETTA, Michel. Concentración y centralización del Capital. Itens: Definición y causas de la concentración del capital. In: Regulación y Crisis del Capitalismo. 3. ed. Ciudad de Mexico: Siglo Veintiuno Editores, 1986. p. 192-197.

BONDUKI, Nabil. Origens da habitação social no Brasil: arquitetura moderna, lei do inquilinato e difusão da casa própria. 6 ed. São Paulo: estação Liberdade, 2013.

CAMARA METROPOLITANA DE INTEGRAÇÃO GOVERNAMENTAL DO RIO DE JANEIRO. Revista Rio Metrópole: charrete metropolitana. Rio de Janeiro, nov./2015.

Revista Rio Metrópole: os desafios e os rumos de gestão das 19 cidades que integram a região. Rio de Janeiro, mai./2011.

CANO, Wilson. Ensaios sobre a crise urbana do Brasil. Campinas: UNICAMP, 2011.

CARLOS, Ana Fani Alessandri. Da "organização" à "produção" do espaço no movimento do pensamento geográfico. In: CARLOS, Ana Fani Alessandri; SOUZA, Marcelo Lopes; SPOSITO, Maria Encarnação Beltrão (orgs). A produção do espaço urbano: agentes e processos, escalas e desafios. São Paulo: Contexto, 2011.

CHESNAIS, François. A mundialização do capital. São Paulo, Xamã, 1996.

DAVIDOVICH, Fany Rachel. Estado do Rio de Janeiro: singularidades de um contexto territorial. In: Anais do VIII Encontro Nacional da ANPUR. Porto Alegre, 1999.

O entorno da região metropolitana do Rio de Janeiro, hipóteses e considerações. In: Anais do IX Encontro Nacional da ANPUR. Rio de Janeiro, ANPUR, p. 326-335, 2001a.

Metrópole e território: metropolização do espaço no Rio de Janeiro. Cadernos Metrópole , Rio de Janeiro, n. 6, $2^{\circ}$ sem., p. 67-77, 2001b.

DOMINGUEZ, Marcos Thimoteo et al. Gestão impositiva versus governança metropolitana: um estudo de caso sobre a FUNDREM. Rio de Janeiro: IPEA, 2014.

FERNANDES, Nelson da Nóbrega. 0 rapto ideológico da categoria subúrbio: Rio de Janeiro 1858-1945. Rio de Janeiro: Apicuri, 2011.

FRETAG, Bárbara. Capitais migrantes e poderes peregrinos: o caso do Rio de Janeiro. Campinas: Papirus, 2009.

GEIGER, Pedro Pinchas. Urbanização e industrialização na orla Oriental da Baía de Guanabara. Revista Brasileira de Geografia, Rio de Janeiro: IBGE, v. 18, n. 4, out./dez. p. 47-74, 1956.

KOWARICK, Lúcio. Escritos urbanos. São Paulo: Editora 34, 2000.

LEFEBVRE, Henri. La production de l'espace. Paris: Anthropos, 2000.

LENCIONI, Sandra. Concentração e centralização das atividades urbanas: uma perspectiva multiescalar. Reflexões a partir do caso de São Paulo. Revista de Geografia Norte Grande, v. 39, p. 7-20, 2008.

Reestruturação urbano-industrial no estado de São Paulo: a região da metrópole desconcentrada. In: Espaço \& Debates, São Paulo, NERU, n.38, p.54-61, 1994.

A metamorfose de São Paulo: o anúncio de um novo mundo de aglomerações difusas. Revista Paranaense de Desenvolvimento, Curitiba, n.120, jan./jun. 2011, p.133-148. MARICATO, Ermínia. Para entender a crise urbana. São Paulo: Expressão Popular, 2015. MARTINS, José de Souza. o cativeiro da terra. 9. ed. São Paulo: Contexto, 2010. 
MENDES, Renato da Silveira. Paisagens culturais da Baixada Fluminense. Tese de Doutorado (Geografia Humana) - Faculdade de Filosofia, letras e Ciências Humanas, Universidade de São Paulo, São Paulo 1950.

MONBEIG, Pierre. O crescimento da cidade de São Paulo. In: SZMRECSÁNYI, Tamás (Org). História econômica da cidade de São Paulo. Porto Alegre: Editora Globo, 2004. p. 14-115.

NATAL, Jorge. Revisitando o Rio de todas as crises: economia, espaços e classes sociais. In: GONÇALVES, Matia Flora; BRANDÃO, Carlos Antônio;

SEABRA, Odette. Urbanização e fragmentação: cotidiano e vida de bairro na metamorfose da cidade em metrópole, a partir das transformações do bairro do Limão. Tese de Livre Docência (Geografia Humana) - Faculdade de Filosofia, Letras e Ciências Humanas, Universidade de São Paulo, São Paulo, 2003.

SOARES, Maria Therezinha de Segadas. Nova Iguaçu: absorção de uma célula urbana pelo Grande Rio de Janeiro. Revista Brasileira de Geografia, Rio de Janeiro: IBGE, v. 24, n. 2, abr./jun. p. 3-104, 1962.

SOBRAL, Bruno Leonardo Barth. Crise e ciclo: limites à capacidade de um crescimento econômico sustentado na periferia metropolitana do Rio de Janeiro diante do ciclo recente de grandes investimentos. Brasília/Rio de Janeiro: IPEA, 2015a. (Texto para Discussão 2143).

O necessário, o possível e o impossível: uma leitura do papel das políticas públicas diante dos limites à coordenação de grandes investimentos na periferia metropolitana fluminense. Brasília/Rio de Janeiro: IPEA, 2015b. (Texto para Discussão 2154).

SOUZA, Marcelo Lopes de. Rio de Janeiro: causas e perspectivas da crise. Revista Princípios. [online]. São Paulo: Editora Anita Guaribaldi, 2018. Disponível em: <HYPERLINK "http:// revistaprincipios.com.br/artigos/32/cat/1825/rio-de-janeiro-causas-e-perspectivas-dacrise-.html"http://revistaprincipios.com.br/artigos/32/cat/1825/rio-de-janeiro-causas-eperspectivas-da-crise-.html>. Acesso em: 06/03/2018.

VIANA, Juliana Nazare Luquez. Evolução e estruturação urbanas de São Gonçalo: do final do século XIX à segunda Guerra Mundial. Dissertação de Mestrado (Geografia) - Instituto Geociências, Universidade Federal Fluminense, Niterói, 2013.

VIANA, Juliana Nazare Luquez. RUPTURAS E CONTINUIDADES. A produção do espaço e o processo de reestruturação: um olhar a partir de São Gonçalo, Região Metropolitana do Rio de Janeiro. 2019. 312 f. Tese (Doutorado em Geografia Humana) - Faculdade de Filosofia, Letras e Ciências Humanas, Universidade de São Paulo, São Paulo, 2019.

\section{NOTAS}

1. Com o termo Metrópole Rio referimo-nos a classificação dada a Cidade do Rio de Janeiro mediante sua polarização e influência em relação as cidades de seu em torno. Distanciamo-nos, assim, da definição utilizada por alguns autores fluminenses (NATAL, 2003; SOUZA, 2018) e pela Câmara Metropolitana de Integração Governamental do Rio de Janeiro $(2011 ; 2015)$ que referemse a Metrópole Rio como sendo o conjunto da Cidade do Rio e sua região de influência.

2. É mister destacar que a natureza das relações sociais de produção constitui-se no principal fator de diferenciação entre as dinâmicas econômicas do Rio de Janeiro e de São Paulo. No Rio de Janeiro, essas relações baseavam-se em uma lógica escravocrata, sendo os exemplos mais claros, a organização do trabalho nos sistemas produtivos do médio Vale do Paraíba e a consolidação de núcleos favelados e periféricos na metrópole e no seu em torno (CAMPOS, 2005). Em São Paulo, as 
relações de produção assalariadas permitiram novos elementos, sob outras lógicas, à organização do trabalho e à recomposição territorial. Tais elementos, todos necessários, a essa nova estruturação da produção: novas relações socais de produção e de reprodução (MARTINS, 2010).

3. Quais sejam: Complexo Siderúrgico do Atlântico (Rio de Janeiro e Itaguaí); Complexo Petroquímico do Rio de Janeiro (Itaboraí e São Gonçalo); Implantação do Arco Metropolitano do Rio de Janeiro (Itaboraí, Magé, Guapimirim, Duque de Caxias, Nova Iguaçu, Queimados, Japeri, Seropédica e Itaguaí); Programa de Modernização e Expansão da Frota (PROMEF), com encomendas de navios petroleiros aos estaleiros da Baía de Guanabara (Rio de Janeiro, Niterói e São Gonçalo).

4. Fundação Centro Estadual de Estatísticas, Pesquisas e Formação de Servidores Públicos do Rio de Janeiro (CEPERJ).

5. Para Kowarick as contradições urbanas se dão em decorrência de os "investimentos públicos em bens de consumo coletivo [serem] tradicionalmente realizados em prejuízo da grande massa dos trabalhadores" (KOWARICK, 2000, p. 23).

\section{RESUMOS}

O presente artigo tem como objetivo analisar os processos de concentração e centralização das atividades urbanas na área metropolitana fluminense na interface das dinâmicas de dispersão e fragmentação de sua conformação espacial. As novas dimensões da lógica de produção do espaço metropolitano inserem-se na relação entre a dinâmica territorial das atividades urbanas e a centralização de comando, gestão e fluxos (materiais e imateriais) e as implicações dessa relação na reestruturação do espaço. Há, portanto, uma tendência e um fato novo na perspectiva da compreensão da produção do espaço metropolitano e sua conformação na urbanização contemporânea. Sendo a tendência a histórica concentração das atividades urbanas na cidade do Rio de Janeiro e com isso o fortalecimento de sua centralidade. O novo repousa no fato de que com a reprodução da metrópole em direção aos eixos principais de sua aglomeração metropolitana, novas centralidades se reforçam através de uma configuração espacial intensificada por integrações regionais cada vez mais determinantes para a reprodução do capital e da manutenção de sua lógica perversa flagrante no processo de produção do espaço e da vida. A reafirmação da centralidade da Cidade do Rio de Janeiro na fase da urbanização contemporânea não aniquila as centralidades em sua área de influência e na periferia metropolitana, contudo, amplia as fossas da fragmentação entre os territórios urbanos da aglomeração, não os desintegrando, ao contrário, fortalecendo uma dinâmica de homogeneização periférica e de hierarquização dominante.

L'article a comme but analyser les processus de concentration et de centralisation des activités urbaines dans la zone métropolitaine de Rio de Janeiro à l'interface des dynamiques de dispersion et de fragmentation de sa conformation spatiale. Les nouvelles dimensions de la logique de production de l'espace métropolitain sont liées à la relation entre la dynamique territoriale des activités urbaines et la centralisation du commandement, de la gestion et des flux (matériels et immatériels) et aux implications de cette relation dans la restructuration de l'espace. Il y a une tendance et un nouveau fait dans la compréhension de la production de l'espace métropolitainLa tendance est à la concentration historique des activités urbaines dans la 
ville de Rio de Janeiro et, partant, au renforcement de la centralisation. Le fait nouveau concerne la reproduction de la métropole vers les principaux axes de son agglomération métropolitaine: les nouvelles centralités sont renforcées par des intégrations régionales de plus en plus décisives pour la reproduction du capital et le maintien de sa logique perverse. La réaffirmation de la centralisation de la ville de Rio de Janeiro dans la phase d'urbanisation contemporaine n'annule pas les autres dans sa zone d'influence et dans la périphérie métropolitaine, elle élargit les fossés de fragmentation entre les territoires urbains de l'agglomération, mais ne les désintègre pas; mais en renforçant une dynamique d'homogénéisation périphérique et d'hiérarchisation dominante.

Este artículo tiene como objetivo analizar los procesos de concentración y centralización de actividades urbanas en el área metropolitana de Río de Janeiro en la interfaz de la dinámica de dispersión y fragmentación de su conformación espacial. Las nuevas dimensiones de la lógica de producción del espacio metropolitano se ajustan a la relación entre la dinámica territorial de las actividades urbanas y la centralización del comando, gestión y flujos (materiales e inmateriales) y las implicaciones de esta relación en la reestructuración del espacio. Hay, por lo tanto, una tendencia y un nuevo hecho desde la perspectiva de entender la producción del espacio metropolitano y su conformación en la urbanización contemporánea. La tendencia es la concentración histórica de las actividades urbanas en la ciudad de Río de Janeiro y, por lo tanto, el fortalecimiento de su centralidad. Lo nuevo radica en el hecho de que con la reproducción de la metrópoli hacia los ejes principales de su aglomeración metropolitana, nuevas centralidades se refuerzan a través de una configuración espacial intensificada por integraciones regionales cada vez más determinantes para la reproducción del capital y el mantenimiento de su lógica perversa en el proceso de producción de espacio y vida. La reafirmación de la centralidad de la ciudad de Río de Janeiro en la fase de urbanización contemporánea no aniquila las centralidades en su área de influencia y en la periferia metropolitana, sin embargo, amplía los pozos de fragmentación entre los territorios urbanos de la aglomeración, no los desintegra, por el contrario, fortalece una dinámica de homogeneización periférica y jerarquización dominante.

The present article aims to analyze the processes of concentration and centralization of urban activities in the metropolitan area of Rio de Janeiro, at the interface of the dynamics of dispersion and fragmentation of its spatial conformation. The new dimensions of the logic production of metropolitan space are related to the relationship among the territorial dynamics of urban activities and the centralization of command, management and flows (material and immaterial) and the implications of this relationship in the restructuring of space. There is, therefore, a new tendency and a new factor in the perspective of the understanding of the production of the metropolitan space and its conformation in the contemporary urbanization. Being the tendency the historical concentration of the urban activities in the city of Rio de Janeiro and with that the strengthening of its centrality. The new factor rests on the reproduction of the metropolis towards the main axes of its metropolitan agglomeration, new centralities are reinforced through a spatial configuration intensified by regional integrations increasingly decisive for the reproduction of capital and the maintenance of its flagrant perverse logic in the process of production of space and life. The reaffirmation of the centrality of the city of Rio de Janeiro in the phase of contemporary urbanization does not annihilate the centralities in its area of influence and in the metropolitan periphery, however, it widens the spaces of fragmentation between the urban territories of the agglomeration, not disintegrating them, strengthening a dynamic of peripheral homogenization and dominant hierarchization. 
ÍNDICE

Mots-clés: restructuration de l'espace; concentration; centralisation; fragmentation territoriale. Keywords: restructuring of space; concentration; centralization; territorial fragmentation.

Palabras claves: reestructuración del espacio; concentración centralización fragmentación territorial

Palavras-chave: reestruturação do espaço; concentração; centralização; fragmentação territorial.

\section{AUTOR}

JULIANA LUQUEZ

Universidade Estadual de Mato Grosso do Sul - UEMS

E-mail: julianaluquez@gmail.br 